DOI: $10.17516 / 1997-1370-0820$

УДК 378.046.4: 378.147

\title{
Perception of Distance Learning by Some Categories of Adults in Ukraine
}

\author{
Sergey E.Zelinskyi* \\ Regional Center for Advanced Training of the Kirovograd Region \\ Ukraine, Kropyvnytskyi (Kirovograd)
}

Received 15.05.2021, received in revised form 24.06.2021, accepted 10.08.2021

\begin{abstract}
The Ukrainian distance education market is less than 15 years old, so it is clear that it is just being formed and has not yet encompassed educational institutions in large quantities: schools, institutions of professional and higher education, postgraduate institutions. But today, during the COVID-19 pandemic, for the modern education system, the issue of transforming the forms and methods of teaching, in particular, its rapid and massive transition to distance learning, is relevant. In order to understand what consequences the system of higher and postgraduate education can expect, studies are being carried out in different countries to study the perception of distance learning, its effectiveness and the prospects for mass application. The article examines the perception of distance learning in the system of advanced training of public servants and teachers, as well as students of Ukrainian higher educational institutions. The results of the study showed that the vast majority of public officials, teachers and students quickly adapted to the new form of education and actively use domestic web platforms for distance courses and various online distance learning systems. At the same time, only a small part of the respondents believe that the level of knowledge they receive through distance learning is lower than in the «face-to-face» format, and a significant part of adults are always ready to study remotely, although the majority of respondents consider it effective and useful for myself a mixed form of study.
\end{abstract}

Keywords: online learning, forms of education, training, face-to-face, e-learning.

Research area: pedagogy.

\footnotetext{
(C) Siberian Federal University. All rights reserved

* Corresponding author E-mail address: s_zel@ukr.net ORCID: 0000-0002-9737-0643
} 


\title{
Восприятие дистанционного обучения некоторыми категориями взрослых в Украине
}

\author{
С.Э. Зелинский \\ Региональный центтр повышения квалификации Кировоградской области \\ Украина, Кропивницкий (Кировоград)
}

\begin{abstract}
Аннотация. Рынку украинского дистанционного образования менее 15 лет, поэтому очевидно, что он только формируется и массово еще не охватил учебные заведения: школы, учебные заведения профессионального и высшего образования, учреждения последипломной подготовки. Но сегодня, во время пандемии COVID-19, для современной системы образования актуален вопрос трансформации форм и методов обучения, в частности ее стремительного и массового перехода к дистанционному обучению. Чтобы понимать, какие последствия могут ожидать систему высшего и последипломного образования, в разных странах проводятся исследования по изучению восприятия дистанционного обучения, его эффективности и перспектив массового применения. В статье исследовано восприятие дистанционной формы обучения в системе повышения квалификации публичных служащих и учителей, а также студентов украинских высших учебных заведений. Результаты проведенного исследования показали, что абсолютное большинство публичных служащих, учителей и студентов быстро адаптировались к новой форме обучения и активно пользуются отечественными веб-платформами дистанционных курсов и различными онлайновыми системами дистанционного обучения. При этом лишь незначительная часть респондентов считает, что уровень знаний, которые они получают при дистанционном обучении, ниже, чем в формате «face-to-face», а значительная часть взрослых готова всегда учиться в дистанционном режиме, хотя большинство респондентов считает эффективной и полезной для себя смешанную форму обучения.
\end{abstract}

Ключевые слова: онлайн-обучение, формы обучения, повышение квалификации, аудиторное обучение, электронное обучение.

Научная специальность: 13.00.00 - педагогические науки

\section{Введение}

Как и во многих странах, в Украине дистанционное обучение нормативно закреплено, например, «Положением о дистанционном обучении» и новой редакцией Закона Украины «О высшем образовании» (принят в 2017 году), а дистанционные технологии обучения используются в большинстве отечественных высших учебных заведений. Но достаточно длительное время дистанционное обучение рассматривалось как незначительная по объему составляющая образовательного процесса, а предпочтение отдавалось традиционным аудиторным занятиям («faceto-face»). Наверное, потому, что в образовании есть две взаимосвязанные важнейшие состав- ляющие - знания и воспитание. Именно эти составляющие объединяются через общение, а как говорил Антуан де Сент-Экзюпери: «Единственная известная мне роскошь - это роскошь человеческого общения».

К сожалению, в условиях коронавирусной пандемии COVID-19, которая охватила весь мир с начала 2020 года, межличностное общение в сфере образования стало дефицитом, потому что перед учебными заведениями для взрослых критической темой стала адаптация учебного процесса к дистанционной форме. Логическим продолжением дистанционного обучения стало онлайн-обучение (e-learning), когда получение знаний и навыков осуществляется с по- 
мощью компьютера или другого устройства, подключенного к интернету. При этом коммуникация может быть либо асинхронной (когда преподавателю и слушателям не нужно одновременно быть в онлайновом режиме), либо синхронной (коммуникация и взаимодействие происходят в режиме реального времени).

После вынужденного массового перехода к дистанционному обучению в мире появилось много критических замечаний и философских суждений о такой форме образования и ее последствиях для обучаемых. Например, профессор итальянской литературы из университета Калабрии Нуччо Ордине в видеообращении, размещенном в мае 2020 года на сайте испанского издания El Pais, высказал мнение о том, что дистанционное обучение - это смерть образования, потому что «через компьютерный экран знания не могут быть ни переданы, ни восприняты по-настоящему».

Чтобы понимать, какие последствия могут ожидать систему высшего и последипломного образования, в разных странах начали проводить исследования по восприятию дистанционной формы обучения, ее эффективности и перспективы массового использования. Хотя в литературе можно встретить различные названия онлайн-образования - «дистанционное обучение», «электронное обучение», «онлайнобучение», «компьютерное обучение», «сетевое обучение», «виртуальное обучение», «киберобучение», но в большинстве случаев онлайн-образование для взрослых разделяется по типам пользователей:

- на университетское онлайнобразование, пользователями которого являются студенты, зачисленные в высшие учебные заведения (вузы);

- на массово открытые онлайн-курсы (Massive Open Online Course - MOOC) для взрослой аудитории по различным тематическим направлениям (Clark, 2016; Khusyainov, 2015; Schroeder, 2012).

К университетскому онлайнобразованию относится и последипломное онлайн-образование в системе повышения квалификации различных категорий (госу- дарственных служащих, учителей, медицинских работников, руководителей предприятий и учреждений и др.). Именно это и является предметом многих исследований, касающихся онлайн-обучения в системе высшего и последипломного образования (Berezhna \& Prokopenko, 2020; Brammer \& Clark, 2020; Grinevich et al., 2020; Hall Owen, 2020; Zelinskyi, 2020). Через несколько месяцев после начала карантина в Украине Государственной службой качества образования Украины был проведен масштабный анонимный опрос (более 28000 респондентов) научно-педагогических работников и студентов вузов всех типов и форм собственности о дистанционном обучении и его последствиях. В этом исследовании сделан вывод о том, что, даже «имея определенный опыт, который приобрели высшие учебные заведения в связи с использованием дистанционной формы обучения в условиях общенационального карантина, о подтверждении практической пользы для системы высшего образования говорить рано», что свидетельствует об актуальности указанной проблемы и важности ее всестороннего и глубокого изучения.

В свое время проблематика и различные аспекты дистанционного обучения в высшем и последипломном образовании рассматривались многими зарубежными исследователями, среди которых А. Кей (Кауе \& Rumble, 2018), Г. Рамбл (Rumble \& Harry, 2018), А. Сан (Sun \& Chen, 2016), Р. Патрик (Rice \& Patrick, 2020). Также вопросы дистанционного образования находятся в поле зрения и украинских, и российских ученых (Shunevych, 2006; Zabolotskyi, 2016; Sysoieva \& Osadcha, 2019; Chirikov et al., 2020; Pekker, 2019; Klimenskikh et al., 2017).

Чтобы выяснить общие вопросы мотивации взрослых (студентов и слушателей) к онлайн-обучению, можно обратиться к результатам некоторых исследований. Например, в одном из российских исследований ответы респондентов, имеющих опыт дистанционного обучения, на вопрос о цели обучения в дистанционном формате распределились следующим образом: саморазвитие $(51,8 \%)$; расширение профессио- 
нальных компетенций $(24,7$ \%); получение документа о повышении квалификации $(8,64 \%) ;$ учебный план $(6,2 \%)$, наличие свободного времени (1,2 \%) (Klimenskikh et al., 2017).

Российские исследователи Высшей школы экономики совместно с коллегами из США проанализировали эффективность дистанционного обучения по сравнению с традиционными занятиями и пришли к выводу, что такой метод преподавания не уступает по качеству традиционному обучению, но при этом позволяет научить на 15-18 \% больше студентов (Chirikov et al., 2020). Также установлено, что при почти равных образовательных результатах затраты на обучение одного студента в смешанном формате оказались меньше на 15-19 \%, а в дистанционной форме - на 79-81 \% в зависимости от курса обучения.

В области оценивания существуют разные мнения относительно измерения эффективности онлайновых курсов, но наиболее распространенным является подсчет количества слушателей, окончивших курс и получивших сертификат. По статистике в среднем только 10-15\% слушателей массовых онлайн-курсов просматривают видеоматериалы, слушают онлайн-лекции, выполняют все задания курса и получают сертификат об окончании.

Некоторые исследования свидетельствуют о том, что дистанционное обучение менее эффективно по сравнению с традиционными «face-to-face» формами преподавания. В частности, об этом говорится в последнем отчете сотрудников Центра образовательной политики в Колледже образования и развития человека Университета Дж. Мейсона (США). В нем отмечается, что большинство слушателей онлайновых курсов не завершают начатое обучение, причем с годами этот показатель только снижается. Если в 2014-2015 годах из всех слушателей онлайн-курсов учебные занятия до конца проходили всего $6 \%$, то в 2016-2017 годах этот показатель был на уровне $4 \%$, а в 2017-2018 годах - только 3,13 \% (Protopsaltis \& Baum, 2019). При этом значительная часть тех, кто оплатил онлайн-курсы, даже не приступает к ним. Авторы исследования составили рекомендации Министерству образования США о том, что сокращение доли традиционного (аудиторного) обучения в пользу дистанционной формы будет нарушением интересов потребителей и ухудшит качество образования в стране в целом.

Достаточно интересны данные исследования (Pekker, 2019), основанные на онлайн-опросе 2665 студентов 17 онлайн-курсов МГУ им. М.В. Ломоносова на платформе «Открытое образование». Это исследование показало, что причины «отсева» слушателей зависят от их первоначальных намерений, а изначальный интерес обучаемых не совпадает с ожидаемым уровнем предлагаемых знаний.

\section{Методология исследования}

Для изучения мнения о восприятии онлайн-обучения взрослыми автором использовались онлайновые анонимные опросники в виде Google-форм. Среди респондентов опросов, которые проводились осенью 2020 года, были:

- публичные служащие органов власти (875 респондентов - государственные служащие и должностные лица местного самоуправления; $\mathrm{N}=875$ );

- учителя школ (901 респондент, из которых 56 \% имели стаж работы в сфере образования более 20 лет, 27 \% - 10-20 лет; $11 \%$ - 5-10 лет; $6 \%$ - до 5 лет; N=901);

- студенты вузов (1560 респондентов, из которых $50 \%$ - это студенты 1-2-го года обучения, $47 \%$ - 3-4-го года обучения, $3 \%$ - 5-6-го года обучения; $\mathrm{N}=1560$ ).

\section{Результаты}

Проведенный опрос позволил выяснить общее восприятие дистанционного формата обучения различными категориями взрослых в Украине. В частности, онлайн-обучение воспринимают как «формализм» почти $25 \%$ респондентов среди публичных служащих (чиновников), более $29 \%$ учителей и $37 \%$ студентов. То, что на время карантина повышение квалификации и обучение вообще должны быть 
прекращены, считают $13 \%$ респондентов из числа публичных служащих, 22 \% учителей и $45 \%$ студентов.

С начала карантина до конца 2020 года только 12,1\% респондентов среди публичных служащих и $17,1 \%$ учителей не прошли ни одного обучения в системе повышения квалификации в дистанционном формате. Среди студентов таких нет. При этом в системе повышения квалификации (чиновники и учителя) около трети респондентов прошли хотя бы одно обучение (курс) в дистанционном формате, а каждый шестой -4 и более обучений. Очевидно, что при продлении карантина в системе повышения квалификации $100 \%$ слушателей пройдут дистанционные курсы и онлайновое обучение.

Распределение ответов на вопрос «Какое время Вы еще готовы учиться в дистанционном режиме?» представлено в табл. 1 . Почти половина учителей и студентов и $3 / 4$ чиновников всегда готовы обучаться в онлайновом формате.

Ответы на вопрос «Насколько Вам было сложно переориентироваться на онлайновый режим обучения?» (табл. 2) сви- детельствуют о том, что для основной массы публичных служащих и студентов переход к онлайновым занятиям не вызвал определенных проблем, а вот для трети учителей этот переход был несколько сложным.

Как показала практика, в дистанционном формате обучения в Украине используется два типа занятий: синхронный (онлайновое обучение в реальном времени, когда преподаватель и слушатели (студенты) одновременно находятся в образовательной среде) и асинхронный (дистанционный формат обучения, когда слушатели (студенты) могут использовать записанные на вебплатформах учебные курсы в любое время). В табл. 3 приведены данные опроса о восприятии различных типов дистанционного обучения.

Данные исследования относительно того, где удобнее проходить дистанционное обучение, свидетельствуют о следующем. Публичные служащие отдают предпочтение обучению на своем рабочем месте (ПК, ноутбук) - 42,1 \%; дома (ПК, ноутбук) $24 \%$; в любом месте (смартфон, планшет) $33,9 \%$. Соответственно, для учителей это: на рабочем месте (ПК, ноутбук) - 17,7 \%;

Таблица 1. Готовность продолжать обучение в дистанционном режиме Table 1. Willingness to continue distance learning

\begin{tabular}{|l|c|c|c|}
\hline \multicolumn{1}{|c|}{ Варианты ответов } & Публичные служащие, $\%$ & Учителя, $\%$ & Студенты, $\%$ \\
\hline Всегда & 73,3 & 48,9 & 45,3 \\
\hline $1-2$ месяца & 11,4 & 25,5 & 14,5 \\
\hline 3-4 месяца & 3,6 & 6,3 & 21,0 \\
\hline 6 месяцев & 4,6 & 6,3 & 11,3 \\
\hline Прекратить немедленно & 7,2 & 13 & 9,7 \\
\hline
\end{tabular}

Таблица 2. Сложность перехода на онлайн-обучение

Table 2. The difficulty of moving to online learning

\begin{tabular}{|l|c|c|c|}
\hline \multicolumn{1}{|c|}{ Варианты ответов } & Публичные служащие, $\%$ & Учителя, $\%$ & Студенты, \% \\
\hline Сложно & 11,4 & 35,9 & 21,0 \\
\hline Просто & 61,3 & 37,4 & 66,1 \\
\hline $\begin{array}{l}\text { У меня были } \\
\text { соответствующие } \\
\text { навыки }\end{array}$ & 27,3 & 26,7 & 12,9 \\
\hline
\end{tabular}


дома (ПК, ноутбук) - 65,6 \%; в любом месте (смартфон, планшет) - 16,7 \%, а для студентов - дома (ПК, ноутбук) - 56,5 \%; в любом месте (смартфон, планшет) - 43,5\%.

Результаты опроса о преимуществах онлайн-обучения показывают, что учителя и студенты наибольшее значение придают «воспитанию самоорганизации» (37,2 \% и 32,3\% соответственно). В то же время чиновники наиболее значимым при дистанционном обучении считают «отсутствие командировок» $(24,6 \%)$ и «присутствие на рабочем месте» $(25,2 \%)$. Как раз последнее и обусловливает основной недостаток в онлайновом формате обучения для публичных служащих - «отвлечение на выполнение текущей работы» (43,2 \%). Но больше всего не устраивает представителей всех 3 категорий респондентов техническое обеспечение онлайнового обучения. Более 40 \% публичных служащих, 65 \% учителей и почти $55 \%$ студентов не устраивает «техническое обеспечение рабочего места» и «качество каналов связи (интернета)».

Среди веб-сервисов для синхронного обучения публичные служащие чаще всего используют: Zoom (64%), Skype
(13,1 \%), Google Meet (8,4\%); учителя Zoom (79,8 \%), Skype (19,7 \%), Google Meet (6,1\%); студенты - Zoom (74,2 \%), Skype (19,4\%), Google Meet (6,5\%).

Среди веб-платформ дистанционных курсов для асинхронного обучения чаще всего публичными служащими используются такие ресурсы, как Prometheus (55,8 \%), EdEra (14,1\%), ВУМ (11,2\%); учителями - EdEra (63,5 \%), Prometheus (37,1\%), Coursera (2,4\%), ВУМ (2\%); студентами - Prometheus (6,5 \%), ВУМ (8,1 \%), MOOC (8,1 \%), Универсариум $(4,8 \%)$, а $71 \%$ - не пользуется вообще.

Уровень знаний, полученных при онлайн-обучении, более половины различных категорий взрослых признает таким, как и при традиционной форме (в аудитории с преподавателем) (табл. 4). При этом 25,1 \% публичных служащих, 27,7 \% учителей и $19,4 \%$ студентов считают, что этот уровень даже выше.

Для повышения эффективности дистанционной формы занятий каждая категория респондентов определила приоритетные меры (суммарное значение больше $100 \%$, так как можно было выбирать несколько ответов):

Таблица 3. Наиболее приемлемые типы дистанционного обучения Table 3. The most acceptable types of distance learning

\begin{tabular}{|l|c|c|c|}
\hline \multicolumn{1}{|c|}{ Варианты ответов } & Публичные служащие, $\%$ & Учителя, $\%$ & Студенты, $\%$ \\
\hline Синхронный & 12,6 & 19,3 & 8,1 \\
\hline Асинхронный & 40,4 & 32,8 & 61,3 \\
\hline Оба приемлемы & 43,6 & 43,5 & 29,0 \\
\hline Оба неприемлемы & 3,4 & 4,4 & 1,6 \\
\hline
\end{tabular}

Таблица 4. Уровень знаний, полученных во время онлайн-обучения, в сравнении с аудиторными занятиями

Table 4. The level of knowledge gained during online learning, compared to classroom activities

\begin{tabular}{|l|c|c|c|}
\hline \multicolumn{1}{|c|}{ Варианты ответов } & Публичные служащие, $\%$ & Учителя, $\%$ & Студенты, \% \\
\hline Такой же самый & 61,5 & 52,8 & 51,6 \\
\hline Выше & 25,1 & 27,7 & 19,4 \\
\hline Ниже & 13,4 & 19,5 & 29,0 \\
\hline
\end{tabular}


- публичные служащие: контроль присутствия слушателей (видеоконтроль) 13,5 \%; выполнение заданий (заполнение форм, предоставление ответов на контрольные вопросы) - 37,5 \%; периодические дискуссии - 35,8 \%; обязательное компьютерное тестирование - 38,9 \%;

- учителя: контроль присутствия слушателей (видеоконтроль) - 16,8 \%; выполнение заданий (заполнение форм, предоставление ответов на контрольные вопросы) - 30,1 \%; периодические дискуссии - 43,1\%; обязательное компьютерное тестирование - $24,7 \%$;

- студенты вузов: контроль присутствия слушателей (видеоконтроль) - 16,1%; выполнение заданий (заполнение форм, предоставление ответов на контрольные вопросы) - 33,9 \%; периодические дискуссии - $29 \%$; обязательное компьютерное тестирование - 40,3\%.

Наиболее эффективными мерами контроля знаний при синхронном онлайновом обучении являются выполнение заданий, периодические дискуссии по проблемным вопросам и обязательное компьютерное тестирование знаний после завершения курса. Например, как показывает практика применения онлайн-обучения, во время повышения квалификации публичных служащих в синхронном режиме текущие задания (например, заполнение Google-форм, оперативные расчеты) выполняют от 50 до $70 \%$ слушателей. Это свидетельствует о том, что только такая часть присутствует за экранами своих компьютеров, хотя компьютерное тестирование, которое проводится по завершении всего курса (учебной программы), проходят все зарегистрированные слушатели.

В табл. 5 приведены данные опроса респондентов о более эффективном и полезном для них обучении. В частности, наибольшая доля всех категорий взрослых таким обучением считает смешанную форму: «традиционное (аудиторное) + дистанционное обучение». При этом традиционное (аудиторное) обучение пользуется спросом только у 14 \% публичных служащих и у четверти учителей и студентов.

\section{Заключение}

Карантинные мероприятия вынуждают заведения высшего и последипломного образования в Украине искать инновационные решения, поэтому за короткий промежуток времени им удалось ввести в практику дистанционное обучение с использованием различных онлайн-сервисов и веб-платформ. Хотя налицо и некоторые недостатки при использовании онлайнзанятий, среди которых технические вопросы и психологические проблемы, но за последний год это является значимым трендом в сфере образовательных услуг.

Пандемия обусловила необходимость внедрения быстрой трансформации педагогической деятельности и методики оценки знаний взрослых. Студенты и слушатели отмечают развитие самоорганизации, возможность получить образование в удобное время и в удобном месте и равный доступ к образованию, независимо от места проживания. При этом активно используется гибкость в выборе наиболее удобных условий обучения, обработка теоретического ма-

Таблица 5. Наиболее эффективное и полезное обучение для взрослых

Table 5. The most effective and useful training for adults

\begin{tabular}{|l|c|c|c|}
\hline \multicolumn{1}{|c|}{ Варианты ответов } & $\begin{array}{c}\text { Публичные } \\
\text { служащие, } \%\end{array}$ & Учителя,\% & Студенты, \% \\
\hline Традиционное (аудиторное) & 14,5 & 25,5 & 25,9 \\
\hline Дистанционное в реальном времени & 14,3 & 10,8 & 25,5 \\
\hline $\begin{array}{l}\text { Записанные курсы } \\
\text { на образовательных веб-ресурсах }\end{array}$ & 29,7 & 17,8 & 33,9 \\
\hline Смешанное & 41,5 & 45,7 & \\
\hline
\end{tabular}


териала на различных онлайн-платформах и индивидуализация учебного процесса. Информационно-коммуникационные технологии помогают повышать уровень познавательной активности взрослых и достигать определенных результатов в теоретических знаниях, практических навыках и формах итогового контроля.

Результаты проведенного исследования показали, что абсолютное большинство публичных служащих, учителей и студентов вузов быстро адаптировались к новой форме обучения и активно используют отечественные веб-платформы дистанционных курсов и различные системы дистанционного обучения. Только незначительная часть респондентов считает, что уровень знаний, которые они получают при дистанционном обучении, ниже, чем в формате «face-to-face», а значительная часть взрослых готова всегда учиться в дистанционном режиме, хотя большинство респондентов считают эффективной и полезной для себя все-таки смешанную форму обучения.

Основываясь на полученных данных, можно утверждать, что эффективное онлайн-обучение зависит от содержания курса, взаимодействия между преподавателем и слушателями (студентами), создания чувства сообщества онлайн-обучения и быстрого развития технологий.

Чтобы приспособиться к длительной пандемии, вузам и заведениям последи- пломного образования потребуются гибкие и эффективные модели обучения, которые позволят адаптироваться к онлайновой образовательной среде. Пандемия COVID-19 ускорила и активизировала долговременные тенденции, а также создала естественный эксперимент, который позволит проверить и оценить определенные инновации и средства обучения.

Почти нет никаких сомнений в том, что онлайн-образованию суждено расти и дальше. В таком случае, скорее всего, следует провести дополнительные исследования для изучения эффективности и улучшения онлайн-обучения. Будущие исследования должны быть сосредоточены на углубленном анализе практики онлайн-обучения, поэтапной реализации наиболее эффективных методов разработки онлайн-курсов. Безусловно, что для получения уточненных результатов воздействия COVID-19 на образовательную деятельность необходимы исследования, которые окончательно определят восприятие взрослыми нового онлайнформата обучения. Но в дальнейшем также должны быть проведены исследования по эффективности практического использования слушателями и студентами знаний и навыков, полученных во время онлайн-обучения, на рабочих местах, результативности и производительности в их деятельности.

\section{Список литературы / References}

Berezhna, S., Prokopenko, I. (2020). Higher Education Institutions in Ukraine during the Coronavirus, or COVID-19, Outbreak: New Challenges vs New Opportunities. In Revista Romaneasca pentru Educatie Multidimensionala, 12, 2, 130-135.

Brammer, S., Clark, T. (2020). COVID-19 and Management Education: Reflections on Challenges, Opportunities, and Potential Futures. In British Journal of Management, 31, 453-456.

Chirikov, I., Semenova, T., Maloshonok, N., Bettinger, E., Kizilcec, R. F. (2020). Online education platforms scale college STEM instruction with equivalent learning outcomes at lower cost. Available at: https://advances.sciencemag.org/content/6/15/eaay5324

Clark, D. (2016). MOOCs: Course Completion is the wrong Measure of Course Success. Available at: https://www.class-central.com/report/moocs-course-completion-wrong-measure

Grinevich, L., Ilyich, L., Morse, N., Proshkin, V., Shemelynets, I., Linyov, K., Riy, G. (2020). Organizatsiya osvitnogo protsesu $v$ shkolah Ukrayini v umovah karantinu: analitichna zapiska [Organization of the educational process in Ukrainian schools under quarantine: an analytical note]. Kyiv: Kyiv University im. Borysa Hrinchenka, 76. 
Hall Owen, P. (2020). Editorial: COVID-19 and the Future of Management Education. GBR, 23, 1, 1-6. Kaye, A., Rumble, G. (2018). Distance Teaching For Higher and Adult Education. London, UK: Routledge.

Khusyainov, T. (2015). Osnovnyie harakteristiki massovyih otkryityih onlayn-kursov (MOOC) kak obrazovatelnoy tehnologii [The main characteristics of mass open online courses (MOOC) as an educational technology]. In Nauka. Mysl [Science. Think], 2, 21-29.

Klimenskikh, M., Vindeker, O., Sheka, A., Korepina, N., Golendukhina E. (2017). K voprosu ob effektivnosti distantsionnogo obucheniya: issledovanie predstavleniy [On the question of the effectiveness of distance learning: a study of representations] In Pedagogicheskoye obrazovaniye $v$ Rossii [Pedagogical education in Russia], 10, 41-47.

Pekker, P. (2019). Reasons for dropout in online training. In Tsennosti i smyislyi [Values and Meanings], 1(59), 139-151.

Protopsaltis, S., Baum, S. (2019). Does online education live up to its promise? A look at the evidence and implications for federal policy. Available at: http://mason.gmu.edu/ sprotops/OnlineEd.pdf

Rice, M., Patrick, R. (2020). Distance education across critical theoretical landscapes: touchstones for quality research and teaching. In Distance Education, 41:3, 319-325

Rumble, G., Harry, K. (2018). The Distance Teaching Universities. London, UK: Routledge.

Schroeder, R. (2012). Emerging open online distance education environment. In Continuing Higher Education Review, 76, 90-99.

Shunevych B. (2006). Teoretichni osnovi distantsiynogo navchannya [Theoretical foundations of distance learning]. Lviv: «Lvivska politekhnika», 200.

Sun, A., Chen, X. (2016). Online education and its effective practice: A research review. Journal of Information Technology Education: Research, 15, 157-175.

Sysoieva, S., Osadcha, K. (2019). Stan, tehnologiyi ta perspektivi distantsiynogo navchannya v vischiy osviti Ukrayini [Status, technologies and prospects of distance learning in higher education in Ukraine]. In Informatsiyni tekhnolohii i zasoby navchannia [Information technology and learning tools], 70, 2, 271-284.

Zabolotskyi, A. (2016). Suchasniy stan distantsiynogo navchannya u VNZ Ukrayini [The current state of distance learning in Ukrainian universities]. In Visnyk Dnipropetrovskoho universytetu im. Alfreda Nobelia. Seriia «Pedahohika i psykholohiia. Pedahohichni nauki» [Bulletin of Dnipropetrovsk University. Alfred Nobel. Series «Pedagogy and psychology. Pedagogical sciences»], 2 (12), 19-23.

Zelinskyi, S. (2020). Onlaynove pidvischennya kvalifIkatsiyi publichnih sluzhbovtsiv: sogodennya i perspektiva [Online training of public servants: present and future]. In Derzhsluzhbovets [Civil servant], 7, 11-16. 